DOI: http://dx.doi.org/10.24093/awejtls/vol1no1.13

\title{
Investigating "Unfaithful" Translations via the Appraisal Theory: A Case Study of Public Notices
}

\author{
Hong Qian \\ The Applied Translation Studies Programme, \\ Division of Humanities \& Social Sciences \\ Beijing Normal University-Hong Kong Baptist University United International College \\ Zhuhai, China
}

\begin{abstract}
It is noticed that some English translations of Chinese public notices are "unfailthful" especially in terms of the linguistic expressions.This article attempts to investigage those English translations and compare them with the source texts via the Appraisal theory. The research questions are as follows: 1) What is the source text producer's appraisal? 2) What is the translator's appraisal? And how is the translator's appraisal reflected in the target texts? 3) What are the differences between the source text producer's appraisal and the translator's appraisal? 4) What are the possible reasons for the translator to choose his/her appraisal and produce "unfaithful" translations? In order to anwer these questions, five Chinese public notices and their English translations which were mainly collected in Hong Kong and Macao are investigated in the present study. The source and target texts are analyzed with the Appraisal theory and then compared to find out their respective appraisal. The findings show that for both Attitude and Engagement parts, the appraisal between source texts and target texts is rather different. Some possible motivations are then explored. It is believed that socio-cultural environment is one of the most important factors influencing translators' decision making in translating public notices. Besides, text types and linguistic conventions also contribute to the "unfaithful" phenomenon.
\end{abstract}

Key Words: Appraisal theory, public notices, reasons, "unfaithful” translation

Cite as: Qian, H. (2017). Investigating "Unfaithful” Translations via the Appraisal Theory: A Case Study of Public Notices. Arab World English Journal for Translation \& Literary Studies, $1(1)$.

DOI: http://dx.doi.org/10.24093/awejtls/vol1no1.13 


\section{Introduction}

Public notices refer to messages and figures released to the public which are closely related with their life, work and other aspects, such as information concerning food, accommodation, transportation, traveling, entertaining and shopping, so on and so for forth. In the international cities like Hong Kong and Macau, bilingual or trilingual (Portuguese is one of the official languages in Macau) public notices can be seen everywhere. When studying these public notices, the author of this article found that some translations of the public notices are not faithful at all compared with their source texts (STs). This phenomenon has aroused the current author's great interest and serves as the starting point of this paper.

According to Zhang (2006) "Public notices are important means and channels for governmental institutions as well as non-governmental institutions to speak to the public. The language(s) in public notices can reflect the identity, attitudes, intentions and expectations of the message sender, and at the same time, reflect the identity of the receiver'(p.29) This paper will take a specific perspective-the message sender's attitude or appraisal to study the "unfaithfulness" of the translations of the public notices. The message sender may refer to the producer of the ST or the translator. In this paper we will mainly focus on the translator's attitude. The appraisal theory, a theory focusing on analyzing attitude, evaluation and stance in texts, will be employed to investigate the unfaithful translations of the public notices. The research questions in this paper are as follows: 1) What is the ST producer's appraisal? 2) What is the translator's appraisal? And how is the translator's appraisal reflected in the Target Texts (TTs)? 3) What are the differences between the ST producer's appraisal and the translator's appraisal? 4) What are the possible reasons for the translator to choose his/her appraisal and produce unfaithful translations?

\section{Appraisal Theory}

\section{Background}

Appraisal theory is an extension and development of Systemic Functional Linguistics (Martin, 1992, ). The framework of Appraisal Theory is a particular approach to describing, exploring and explaining the way "language is used to evaluate, to adopt stances, to construct textual personas and to manage interpersonal positioning and relationships" (White, 2001, p.1). The model of Appraisal theory consists of three parts: Attitude provides a possibility to explore different kinds of values that are encoded in the discourse; Engagement is "concerned with the linguistic resources by which speakers/writers adopt a stance towards the value positions being referenced by the text and with respect to those they address" (Martin \& White, 2005, p. 92); and Graduation reveals how attitudes are expressed by degree. Each part has its own sub-dimensions. Within Attitude, there are Affect, Judgment and Appreciation; within Engagement, there are Monogloss and Heterogloss; within Graduation, there are Force and Focus. This paper will mainly adopt the domain of Attitude and Engagement as the analytical framework. Therefore, Graduation will not be elaborated here.

\section{Attitude}

As the core part of Appraisal Theory, Attitude refers to "those utterances which can be interpreted as indicating that some person, thing, situation, action, event or state of affairs is to be viewed either positively or negatively"(White, 2001, p.1). Utterances regarded as attitudinal in a 
degree are inviting readers to supply their own negative or positive assessments. Here readers, when interpreted in translation studies, include ST and TT readers and TT translators.

Affect is the resource deployed for construing emotional responses ('happiness, sadness, fear, loathing', etc.) (Martin, 2000, p.145). It is associated with emotion indicating positive or negative views through either the speakers/writers' emotional responses reflected in reports or the emotional responses of the third parties'. Affect can be investigated via three major variables: un/happiness, in/security and dis/satisfaction. The un/happiness variable refers to emotions associated with 'affairs of the heart' such as sadness, anger, happiness and love. The in/security variable refers to emotions associated with ecosocial well-being such as anxiety, fear, confidence and trust. And the dis/satisfaction variable refers to emotions associated with the pursuit of goals such as ennui, displeasure, curiosity and respect. "Affect's values are sometimes construed as qualities (adjectives 'I am happy about that.'), sometimes as processes (verbs 'This pleases me') and sometimes as comment adjuncts ('happily'). They may also be realized as virtual entities (nouns) via nominalization 'happiness"' (White, 2002, p.6).

Judgment is deployed for construing moral evaluations of behavior ("ethical, deceptive, brave', etc.) (Martin, 2000, p.145). Just like Affect it has a positive and negative dimension. It is divided into two major groups - social esteem and social sanction. "Judgments of esteem have to do with normality (how unusual someone is), capacity (how capable they are), and tenacity (how resolute they are); judgments of sanction have to do with veracity (how truthful someone is) and propriety (how ethical someone is)" (Martin, 2000, p.156). There are clear distinctions between social esteem and social sanction. Related with admiration and criticism, social esteem has no legal implications; on the other hand, social sanction often has legal implications since it is associated with praise and condemnation. Assessed by reference to some system of social norms, Judgment indicates how people should and should not behave. It is greatly shaped by the particular cultural and ideological situation in which it operates. The way people make Judgments can be determined by the culture they live and by their own individual experiences, expectations, assumptions and beliefs. "So there's always the possibility that the same event will receive different Judgments, according to the ideological position of the person making those Judgments" (White, 2001, p.2). The words such as "immoral, virtuous, honest, brutal, lawabiding, etc." are indications of Judgment.

Appreciation 'construes the 'aesthetic' quality of semiotic text/processes and natural phenomena ('remarkable, desirable, harmonious, elegant, innovative', etc.)" (Martin, 2000, p.146). Like Affect and Judgment, it also has a positive and a negative dimension. Appreciation is concerned with norms about how products, performances, and naturally occurring phenomena are valued. There are three variables in Appreciation: reaction, composition, and valuation. "Reaction has to do with the degree to which the text/process in question captures our attention (reaction: impact) and the emotional impact it has on us. Composition has to do with our perceptions of proportionality (composition: balance) and detail (composition: complexity) in a text/process. Valuation has to do with our assessment of the social significance of the text/process."(Martin, 2000, p.160). Generally speaking, the most obvious values of Appreciation are concerned with what is traditionally known as aesthetics, with people making assessment on the form, appearance, construction, presentation or impact of objects and entities 
(White, 2001, p.1). The terms such as "lovely, harmonious, plain, boring" are examples of Appreciation.

The Attitude part of Appraisal theory can be illustrated in the following figure:

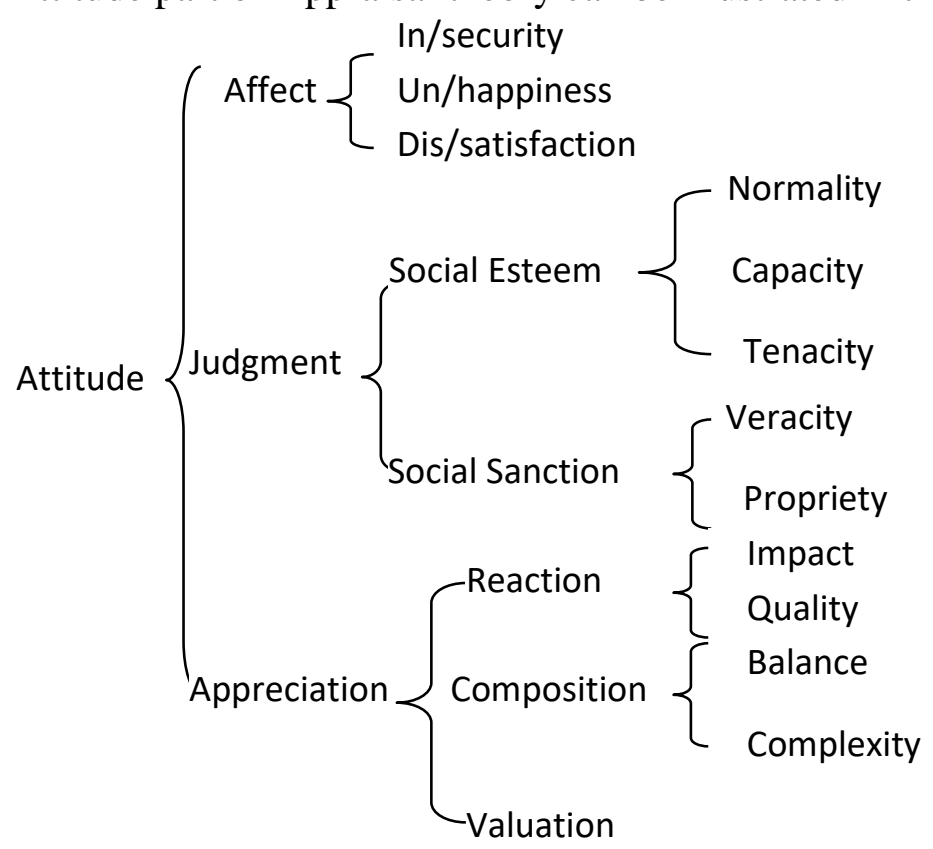

Figure 1. Attitude ( according to Martin, 2000, p.165 \& Wang, 2004, p.32)

Affect, Judgment and Appreciation are three indispensable parts to constitute Attitude subsystem as an effective means to investigate people's positioning. Although divided into three categories, they are "fundamentally interconnected in that they are all to do with the expression of "feelings"" (White, 2002, p.4). On the other hand, each dimension has its own focus. In terms of subjectivity, Affect is more subjective, as it is related with people's emotions. Judgment is less subjective in that its appraising norms are conditioned by socio-cultural environment. Appreciation is also more objective because the 'feelings' are expressed as objects' qualities. In White's (2002) words.

Under Affect, the action of emotion is directly indicated-feelings are presented as the contingent, personalized mental reactions of human subjects to some stimulus. But under both Judgment and Appreciation, these 'feelings' are institutionalized in some way and are recast as qualities which inhere in the evaluated phenomenon itself (p.5).

The distinction between Judgment and Appreciation is that "under Judgment, feelings are reconstrued as proposals about correct behavior - how we should or should not behave...Under Appreciation, feelings are reconstrued as propositions about the value of things" (White, 2002, p.5).

\section{Engagement}

Engagement is a framework that enables people to analyze how various positioning are achieved linguistically. Specifically, it studies "the degree to which speakers acknowledge these prior speakers"; "the ways in which they engage with them"; whether speakers "present 
themselves as standing with, as standing against, as undecided, or as neutral with respect to these other speakers and their value positions" and "whether the value position is presented as one which can be taken for granted for this particular audience, as one which is in some way novel, problematic or contentious, or as one which is likely to be questioned, resisted or rejected" ( Martin \& White, 2005, p.3).

Under Engagement, there are two subsystems: "monoglossic" and "heteroglossic". Monoglossic is propositions that are construed as "either having no alternatives or challenges at all, or as having no alternatives or challenges which need to be acknowledged or engaged with in the current communicative context" (White \& Sano, 2006). Heteroglossic is employed to "label all formulations which, in these and other ways, acknowledge that the utterance operates against a heteroglossic backdrop and present the speaker as recognizing or engaged with other voices and other view points within this backdrop" (White \& Sano, 2006).

One more thing that needs pointing out is that although the examples given above are all at lexical level, such as "happy, lovely, handsome", etc., the appraisal system in general can not only be construed via individual words, but "can be directly construed in text, or implicated through the selection of ideational meanings which redound with affectual/appraising meanings. As a consequence, it is better to see Attitude as a feature or property, not of individual words (though individual words may be 'attitudinal'), but of complete utterances, of stretches of language which present a complete proposition or proposal."(White, 2001, p.2) Therefore, attitude can be reflected at several levels ranging from lexis, phrases, clauses, paragraphs to discourses.

In next section, we will firstly analyze five public notices and their translations in order to investigate the appraisal of ST author and TT translator and explore possible reasons that cause the differences between ST and TT. According to Holmes, (1988), as an empirical discipline, translation studies:

has two main objectives: (1) to describe the phenomena of translating and translation(s) as they manifest themselves in the world of our experience, and (2) to establish general principles by means of which these phenomena can be explained and predicted.(1988, p.71).

Therefore, this paper aims to describe and explain these translation phenomena which were collected from real life without commenting on the quality of the translation. In the following cases, Chinese versions are STs and English versions are TTs. In Macau, Chinese is the official language, but English is not. So for the bilingual public notices in Macau, Chinese version is regarded as the ST. In Hong Kong, both Chinese and English are their official languages. In this case, we assume Chinese versions are the STs and English versions are the TTs. Since our main aim is to investigate the possible factors that cause the unfaithfulness, which one is the ST will not affect our analysis. 
AWEJ for translation \& Literary Studies volume, 1 Number 1, March 2017

Investigating "Unfaithful” Translations via the Appraisal Theory

\section{Case Study}

\section{Define Translation}

Before the case analysis, we will first of all define "translation". Traditionally translation was regarded as "the replacement of textual material in one language (SL) by equivalent textual material in another language (TL)" (Catford, 1965, p.20); or "translating consists in reproducing in the receptor language the closest natural equivalent of the source-language message, first in terms of meaning and secondly in terms of style"(Nida \& Taber , 1969/1982, p.12). However, with the emergence and flourishing of functionalist approach to translation studies, some people begin to pay more attention to the function of texts. As a result, translation is also endowed with new meaning. As one of the representatives of this school, Nord(1991) defines translation as "the production of a functional target text maintaining a relationship with a given source text that is specified according to the intended or demanded function of the target text (translation skopos)" (p.28) . According to the definition of functionalist school, we consider the following cases as translations. And since there exist discrepancies between ST and TT in terms of their content, which is not in accordance with the traditional view of translation and "equivalent" principle, these translations are deemed as "unfaithful".

Now we will employ the Appraisal theory to analyze the ST and TT of five public notices and explore some possible reasons behind this "unfaithfulness".

\section{Case Analysis}

The following five public notices are the cases that this paper will study. These five public notices are regarded as typical cases. They are all texts in use, and the STs and TTs are full texts without any change. ( LT= Literal Translation, the appraisal words are in bold )

\section{Example 1}

\section{ST: 醒目旅遊, 快樂優悠。}

LT: Travel cautiously; you will be happy and carefree.

TT: Be a smart traveler.

Example 1 is a public notice collected in Hong Kong International Airport. ST (Chinese) consists of two clauses, and three adjectives are used, which are “醒目, 快樂, 悠遊”. The appraised target is tourists. Among the three adjectives, two of them (快樂, 悠遊) indicate Affect, and the variable used for appraisal is "happiness". The other one (醒目) is an adjective indicating Capacity on the dimension of Judgment. These appraisal words employed in the ST are aimed to remind the travelers to take care of their own belongings and personal safety during their travel. And only in this way, can they really enjoy a carefree holiday. In contrast, there is only one clause and one adjective (smart) used in TT (English), which indicates Appreciation on Quality. The appraised target is still tourist, however, compared with the appraisal in ST, the appraised dimension has changed from Affect and Judgment to Appreciation. The TT stresses more on people's own responsibility for their personal safety. For the Engagement part, both ST and TT are monogloss, which allows no alternative in their statement, since it is an "advice" for 
travelers. But the difference between ST and TT lies in their sentence pattern. ST engages with its readers with its declarative sentence while TT engages with its readers with an imperative sentence. Although the ultimate aim is to catch the reader's eyes and to remind them, the appraisal devices used in ST and TT are greatly different no matter in terms of Attitude or Engagement.

Example 2

\section{ST: 歡迎光臨全球最佳機場。}

LT: Welcome to the World's Best Airport.

TT: Relax and enjoy the World's Best Airport.

Example 2 is also a public notice collected in Hong Kong International Airport, which is a slogan of this airport. There are three appraisal words used in ST (Chinese), which are “歡迎, 光臨, 最佳” and the appraised target is the airport. Among the three appraisal words, two of them are on the dimension of Affect, indicating a "happy” Affect. “最佳” is used to indicate the Quality, which is an appraisal of the airport on the dimension of Appreciation. “歡迎, 光臨”, are most typical words used in Chinese in welcome guests, expressing the happiness and a sense of honor of the host. For TT (English), also three appraisal words are employed, which are "relax, enjoy, best". The last word "best" can be regarded as a literal translation of its ST “最佳”, but the other two appraisal words are totally different in meaning, although they also indicate happiness on the dimension of Affect. "Relax" and "enjoy" are appraisal words expressing the traveler's felling and the airport's consideration on their footing. Nowadays, many people fly from one place to another for business and are always in a tense mood. But Hong Kong Airport, through its slogan, indicates that it can turn an exhausting and tedious journey into a pleasant by providing a comfortable and relaxing environment. In terms of Engagement, both ST and TT are monogloss. ST engages with its target readers with a declarative sentence, whereas TT engages with its target readers with an imperative sentence, although both ST and TT all indicate the hospitability of Hong Kong International Airport.

Example 3

\section{ST: 即使看來微不足道, 我們也為你用心做好。}

LT: Even if it seems trivial, we will still do it for you heart and soul.

TT: Service: it's all about the little things.

Example 3 is a public notice collected in Hong Kong. ST (Chinese) is comprised of two clauses, in which three appraisal words are employed, and they are “微不足道 , 用心 , 做好”. Among them, the appraised target of “用心” is the company (or an institution) that post this public notice. The appraised targets of “微不足道” and “做好” are “things”. “微不足道” is an appraisal word indicating "Tenacity" on the dimension of Judgment and “做好” is an appraisal 
word indicating "Quality" on the dimension of Appreciation. The three appraisal words respectively from different angles show the company/institution's commitment to the client. In contrast, in TT(English), although the same commitment is also made, only one appraisal word is used-“little”, which is almost an equivalent of “微不足道” in ST, indicating the complexity on the dimension of Appreciation, and the appraised target is "things". The appraisal on Judgment and Appreciation are absent in TT. For the part of Engagement, in this example, both ST and TT Both ST and TT are monogloss, and both of them engage with their readers with declarative sentences, which can be seen as their declaration for providing good service.

Example 4

\section{ST: 減廢回收最環保汗者自付齊贊好。}

LT: Reducing and recycling waste are most environmentallyfriendly,

Making the polluters pay is praised by all.

TT: Reduce waste. Make Polluters Pay.

Example 4 is a public notice collected in Macau to promote environment protection. Sharp contrast exists between ST and TT for both parts of Attitude and Engagement. For ST, there are two clauses, each having an appraisal, which are respectively are “最環保” and “齊贊好”. The two appraisal words indicate "Impact" on the dimension of Appreciation and their appraised targets are correspondingly the "behavior" of reducing producing waste and recycling, and the "policy" of making polluters pay. In this example, the ST is a heterogloss, and it is contractive. As we have mentioned above, contractive heterogloss means that firstly it is a dialogue with its readers in a more active way, and secondly it excludes other alternatives in a contractive manner. For TT, it has omitted all the appraisal words. Although it also has two clauses, they are monogloss and it engages with its readers with two short imperative sentences "reduce waste" and "make polluters pay".

\section{Example 5}

ST:

大臺北, 九折擾待, 母親節, 至靚大蛋糕, 去表達您...一份溫馨至愛心意, 祝 母親健康快樂，5月11日 (星期日)。

LT: Top Taipei Bakery, 90\% offer, on Mother's Day. Buy the best and the most beautiful big cake to express your...most loving feeling, wishing mother healthy and happy, May 11 (Sunday).

TT: Happy Mother's Day, May 11 (Sunday), A special Cake to Mom with Love... 90\% Offer at TOP TAIPEI BAKERY

Example 5 is a public notice collected in Macau, which is in fact an advertisement of a bakery, promoting cakes for Mother's Day. In ST ( Chinese ), eight appraisal words are used, which are “大, 優待, 至靚, 大, 溫馨, 至愛, 健康, 快樂”. The eight appraisal words 
altogether create a sweet and warm atmosphere for this public notice, attracting potential client to buy a cake. “健康，快樂” indicate “Happiness” on the dimension of Affect, “優待” indicates “Normality” on the dimension of Judgment, “大, 至靚, 打, 溫馨 , 至愛” are all indication of Quality on the dimension of Appreciation. The appraised target of the first "大” is “臺北” bakery, the appraised target of “優待” is the price of the cake; the appraised target of “優待” is the price of the cake; the appraised target of “至靚, 大” is the cake; “溫馨, 至愛” are used to appraise feeling and the appraised target of the last two words “健康, 快樂” are “mother". Compared with ST, TT (English) although also promotes cakes for Mother's Day, the appraisal words are much less. There are four altogether indicating the translator's attitude: "happy, special, love and top". The appraised target of "happy" is mother, which is the same as in ST, and it is also on the dimension of Affect, indicating Happiness. For the appraisal word "special", its appraised target is cake, and it indicates "Normality" on the dimension of Judgment. The client is the appraised target of "love" and "top" is used to appraise the bakery. "love" indicates Happiness on the dimension of Affect and "top" is an indication of Quality on the dimension of Appreciation. Compared with ST, the appraisal on cakes and feeling is absent in TT. Both ST and TT are monogloss and declarative sentences, publicizing their cakes.

\begin{tabular}{|c|c|c|c|c|c|c|}
\hline & Dimension & Variable & ST & Appraised & TT & Appraised \\
\hline \multirow{13}{*}{ Attitude } & \multirow[t]{3}{*}{ Affect } & Un/happiness & $\begin{array}{l}\text { 1: } \\
\text { 快樂、優悠； } \\
\text { 2: 歡迎、光 } \\
\text { 臨 } \\
\text { 5: 健康、快樂 }\end{array}$ & $\begin{array}{l}\text { tourist } \\
\text { airport, } \\
\text { mother }\end{array}$ & $\begin{array}{l}\text { 2: relax, } \\
\text { enjoy } \\
\text { 5: happy, } \\
\text { love }\end{array}$ & $\begin{array}{l}\text { traveler } \\
\text { mother } \\
\text { client }\end{array}$ \\
\hline & & In/security & & & & \\
\hline & & $\begin{array}{l}\text { Dis/satisfactio } \\
\mathrm{n}\end{array}$ & & & & \\
\hline & \multirow{5}{*}{ Judgment } & Normality & 5: 優待 & client & 5: special & cake \\
\hline & & Capacity & 1: 醒目 & tourist & & \\
\hline & & Tenacity & 3: 用心 & company & & \\
\hline & & Veracity & & & & \\
\hline & & Propriety & & & & \\
\hline & \multirow{5}{*}{ Appreciation } & Impact & $\begin{array}{l}\text { 4: 最環保 } \\
\text { 4: 齊贊好 }\end{array}$ & $\begin{array}{l}\text { behavior } \\
\text { policy }\end{array}$ & & \\
\hline & & Quality & $\begin{array}{l}2: \text { 最佳 } \\
3: \text { 做好 } \\
5: \text { 大 } \\
5: \text { 至靚、大 } \\
5: \text { 溫馨、至愛 }\end{array}$ & $\begin{array}{l}\text { airport } \\
\text { thing } \\
\text { bakery } \\
\text { cake } \\
\text { feeling }\end{array}$ & $\begin{array}{l}\text { 1: smart } \\
2: \text { best } \\
\text { 5: top }\end{array}$ & $\begin{array}{l}\text { tourist } \\
\text { airport } \\
\text { bakery }\end{array}$ \\
\hline & & Balance & & & & \\
\hline & & Complexity & 3: 微不足道 & thing & 3: little & thing \\
\hline & & Valuation & & & & \\
\hline \multirow[t]{2}{*}{ Engagement } & \multirow[t]{2}{*}{ Monogloss } & Declarative & $1,2,3,5$ & & 3,5 & \\
\hline & & Interrogative & & & & \\
\hline
\end{tabular}


AWEJ for translation \& Literary Studies volume, 1 Number 1, March 2017

Investigating "Unfaithful" Translations via the Appraisal Theory

\begin{tabular}{|l|l|l|l|l|l|l|}
\hline & & Imperative & & \multirow{2}{*}{} & $1,2,4$ & \\
\cline { 3 - 4 } & & Exclamative & & & \\
\cline { 2 - 4 } & \multirow{2}{*}{ Heterogloss } & Expansive & & & & \\
\cline { 3 - 4 } & & Contractive & 4 & & & \\
\hline
\end{tabular}

Figure 2, Appraisal Comparison between STs and TTs on the parts of Attitude and Engagement

Figure 2 is a comparison between STs and TTs on the parts of Attitude and Engagement. For the part of Attitude, it can be seen that there are much more appraisal words in STs than those in TTs, and the number of appraised targets in STs is more than that in TTs. Besides, more variables are involved in STs when appraising the STs authors' attitudes. But in TTs, the variables like "capacity", "tenacity" and "impact" are absent in TTs. For the part of Engagement, there are also some differences. In terms of monogloss and heterogloss, four STs of the five examples are monogloss, and example four is a heterogloss. In contrast, all the five TTs are monogloss. Furthermore, all the four monoglossic STs are declarative sentences, but only two TTs are declarative, with the other three being imperative. However, imperative sentence is absent in STs. From the above case analysis and Figure 2, we can find great difference exist between STs and TTs, especially when inspected via the appraisal theoretical framework. In the following section, we will explore some possible reasons that may cause this kind of unfaithful translation.

\section{Discussion}

Up to today, the issue of "fidelity" in translation studies has gradually faded out of scholars' focus. After translation studies has developed into a comprehensive and interdisciplinary discipline, scholars are more concerned about how to explain translation phenomena instead of setting norms to define what a faithful translation is. It has to be admitted that if translators meet with translation problems which are caused by incompetence in language or cultural knowledge, or being lack of references, TTs may be unfaithful to the STs, and the translators' attitude may deviate from the ST authors' attitude. But this is related with translators' competency, which will not be included in this paper's discussion. In the following part, efforts will be devoted to probe into some possible reasons that may cause the "unfaithful" translation.

\section{The Translator's Subjectivity}

Having described and analyzed the attitudes expressed in the ST and the TT with the help of Appraisal Theory, we can find that the appraising words are greatly different between the ST and the TT, although the appraised targets may be the same. As we have mentioned, according to Appraisal theory, when an author comments on a matter, he/she actually wishes that readers could also provide their points of view, "speakers/writers would position themselves intersubjectively with respect to other speakers and with respect to potential respondents to the current communication" (White \& Sano, 2006). Or according to Martin, "the expression of attitude is not, as is often claimed, simply a personal matter - the speaker 'commenting' on the world - but a truly interpersonal matter, in that the basic reason for advancing an opinion is to elicit a response of solidarity from the addressee." (2000, p.143). Therefore, as the reader of the ST, the translator, will in the first place appraise ST. As a result, the translator's personal opinion or style will be weaved into the TT.

During the translation process, translators are in the first place readers. As a result, they will inevitably give their own appraisal on ST, and personalize some attitudes in TT. For example, in 
Example 5, the translator evaluates the cake as “至靚大蛋糕” (the best and big cake), but there are no such appraising words or even words implying such meaning in ST. The translator challenges the attitudes in ST and provides his/her evaluation instead, which describes the cake as a "special" one.

\section{Different Contexts of Situation}

The context of situation of a text may exert great influence on the translator's translation and appraisal. By context of situation, Malinowski "meant the environment of the text" (Halliday \& Hasan, 1985, p.6). Halliday adopts three variables to describe and interpret the social context of a text, and "the environment in which meanings are being exchanged" (Halliday \& Hasan, 1985, p.6). The three variables are respectively field, tenor and mode, or register variables. Generally speaking, field refers to what is going on; tenor refers to who is taking part, their statuses and roles, and mode refers to the channel through which the speaker and the reader communicate. The analysis of the three variables may shed some light on the translator's unfaithful translation. For instance, in example 2, the field of the ST is a public notice for travelers, showing the airport's hospitality towards them. The tenor of the ST is the airport and travelers speaking Chinese, and the mode is a formal and written form. For the TT, the field is also a public notice for travelers, but more focusing on the comfort and good service of the airport. The tenor of the TT is the airport and the travelers speaking English, and the mode is between formal and informal; the language is more colloquial than written. With different field, tenor and mode, the translator will accordingly provide different appraisal. When the readers are English speakers, the degree of the formality of the public notice is decreased by the translator, and more emphasis is placed on the comfortable environment of the airport by using the appraisal words "relax" and "enjoy". These can meet the expectation horizon of the TT readers, which will be elaborated later in this paper. The analysis of contexts of situation of the STs and TTs can in a degree explain the unfaithful translation of the public notice.

\section{Different Contexts of Culture}

\section{Target readers' expectation horizon}

Jauss (1982), the father of Reception Theory, categorized readers' expectation horizon into two groups: life and literature. The expectation horizon of life includes reader's social status, personal situation, educational background, life experience, values, morality, characters and temperament (as translated in Jin, 1987, p.72). With different expectation horizons, different readers have different requirements on what they read.

In our above examples, in order to meet target readers' expectation horizon, some changes have been made in TT, especially in attitudinal aspect. For instance, in Example 2, ST's reader is Chinese, that is why the most traditional diction “歡迎光臨” is used to express the airport's attitude towards the travelers. These appraisal words indicate that the airport feels honored to have the travelers coming to their company and the travelers are welcomed by them. It is because in China people stress very much on "face" and "respect". When people feel respected and having face, their expectation horizon can be well met. However, "face" principle does not apply to English speakers. What they expect is something more practical, especially when they come a long way from their country to Hon Kong or have experienced an exhausting journey. That is probably why the translator renders the ST into "relax" and "enjoy", a totally different appraisal from that in ST. 


\section{Different socio-cultural values}

Different cultural background and values between the West and China have a profound influence on translation, and greatly contribute to the "unfaithfulness" of the TT. In this paper, this point is mainly reflected on different appraisals. A typical example is the translation of example 4. In example 4, two appraisal words are used in ST, which are “最環保” and “齊贊好”. The first one is the author's attitude towards reducing and recycling waste, and the second is the author's appraisal towards the policy of making the polluters pay. "Praised by all" is a reflection of the ST readers' cultural environment and cultural values - the attachment of importance to collective opinion. For the TT readers, who are English speakers, more influenced by the spirit of "equality and individuality", law and regulations speak much louder than a collective opinion. That is why the appraisal words “齊贊好” get omitted in TT, and that is also why the TT is so unfaithful to the ST.

\section{Different Linguistic Characteristics}

Different linguistic conventions may also lead to the differences between STs and TTs in terms of speaker's appraisal. English and Chinese belong to two different language systems, so that great differences exist between the two languages. These differences will inevitably result in the differences between STs and TTs. One of the characteristics of English is to use large amount of abstract diction. But compared with English, Chinese tends to use concrete diction, to express abstract concept in a concrete form or with a concrete image. When Chinese is translated into English, the different kinds of linguistic convention will be taken into account by the translator and further be reflected in terms of appraisal words, since most of the appraisal words are adjectives or adverbs. A typical example is in Example 5. In ST the cake is described as “至靚大”, which means the cake is the best, the most beautiful and very big. When translated into English, the cake becomes "special", an abstract word. A concrete image thus has been transformed into an abstract concept, and the "special" word also delivers a different appraisal.

Besides, in terms of sentence pattern, in Figure 2, it can be found that there are more imperative sentences in TT than in ST. In a genre like public notice, Usually in Chinese, declarative sentences can be used to reflect the authority or commitment of the text producer. But in English, usually more imperative sentences will be used to reflect the humane care and the advocate of equality and the spirit of serving the customers as God. That is why different ways of engagements have been employed in STs and TTs.

\section{Implications and Conclusion \\ Implications}

By applying Appraisal theory, especially the Attitude and Engagement subsystem, the speaker's attitudes towards some issues can be clearly revealed. In terms of translation practice, this requires that the translator should at first carefully think about the speaker's attitude in ST. With the ST speaker's attitude ascertained, then the translator can decide how to transfer and translate the ST attitude into TT according to different contexts of situation and contexts of culture. Besides, when the attitudes in ST are different from those in TT, TT may appear 
unfaithful to ST, there may be profound reasons for this "unfaithfulness". So the quality of a translation can not only be judged by its faithfulness to the text. A seemingly unfaithful translation of a text may well perform its function as a translated text.

\section{Conclusion}

Appraisal Theory altogether includes three parts: Affect, Engagement and Graduation. In this paper, two parts of the Appraisal Theory-Attitude and Engagement - are employed to analyze STs and TTs. In Attitude, there are three dimensions: Affect, Judgment and Appreciation and In Engagement there are two dimensions: Monogloss and Heterogloss. After a comparative analysis, it can be found that in terms of Attitude and Engagement, there are many differences between ST and TT. One of the possible reasons is that as the first reader, the translator first of all has provided his own appraisal consciously or unconsciously. As Appraisal Theory holds that reading is actually an interpersonal process, during which readers are invited to give their opinions or evaluations. Besides, different contexts of situation, contexts of culture and linguistic conventions have also played important roles in incurring these differences. The analysis of the three variables "field, tenor and mode" shows that different contexts of situation require the translator to provide different appraisal towards the same issue. In different contexts of culture, with different expectation horizons and socio-cultural values, ST readers and TT readers may have different expectations on the same issue or the same place. Different linguistic conventions also serve to the different appraisal in STs and TTs, for example, imperative sentences are used much more often in English than in Chinese. All these can in a degree explain the unfaithful translation of these public notices.

\footnotetext{
About the Author:

Dr. Hong QIAN is now working as assistant professor at Beijing Normal University-Hong Kong Baptist University United International College. She received her PhD degree from the English Department, University of Macau. Her main research interests are Translation Studies, Media Translation, Discourse Analysis and Cross Cultural Studies.
}

\section{References:}

Catford, J. C. (1965). Linguistic Theory of Translation: An Essay in Applied Linguistics. London: Oxford University Press.

Halliday \& Hasan. (1985). Language: Context and Text. Burwood: Deaken University. Holmes, J. S. (1988). Translated! - Papers on Literary Translation and Translation Studies. Amsterdam: Rodopi.

Jauss, H. R.(1982). Aesthetic Experience and Literary Hermeneutics. (Y.P.Jin \& N.Zhou, trans.). Shenyang: Liaoning People Press.

Martin, J. R.(1992). English Text. Amsterdam: John Benjamins

Martin, J.R. (2000). Beyond Exchange: APPRAISAL Systems in English. In Hunston, S. \&

Thompson, G. (Eds.), Evaluation in Text. Oxford: Oxford University Press.

Martin, J.R. \& White, P. R.R.. (2005). The Language of Evaluation-Appraisal in English. Hampshire \& New York: Palgrave Macmillan.

Nida, E. A. \& Taber, C. R. (1969). The Theory and Practice of Translation. Leiden: E.J.Brill. Nord, C.(1991). Text Analysis in Translation: Theory, Methodology, and Didactic 
Application of a Model for Translation-oriented Text Analysis. Amsterdam-Atlanta: Rodopi. Reiss, K. (2004). Translation Criticism - the Potentials \& Limitations. (E. F.

Rhodes,.Trans.). Shanghai: Shanghai Foreign Language Education Press.

Wang,Z.H. (2004). The Study of Attitude in 'Hard News'. Journal of Foreign Language

Teaching, (5): 31-36.

White, P. (2001). Introductory Guide to Appraisal. Retrieved from http://www. grammatics.com White, P. (2002). Appraisal-the Language of Evaluation and Stance. in J.Verschueren, J.Östman, , J.Blommaert, \& C. Bulcaen(Eds.). The Handbook of Pragmatics (1-27). Amsterdam/Philadelphia: John Benjamins Publishing Co..

White, P. \& Sano, M.(2006). Dialogic Positions and Anticipated Audiences-A Framework for Stylistic Comparisons, in K.Aijmer \& A.Simon-Vandenbergen (Eds.), Pragmatic Markers in Contrast (Studies in Pragmatics II), Amsterdam \& Boston: Elsevier.

Zhang, M.F. (2006). Investigating the Languages and Translations of Public Notices in Macao. Shanghai Journal of Translators, (1), 29-34.

Appendix:

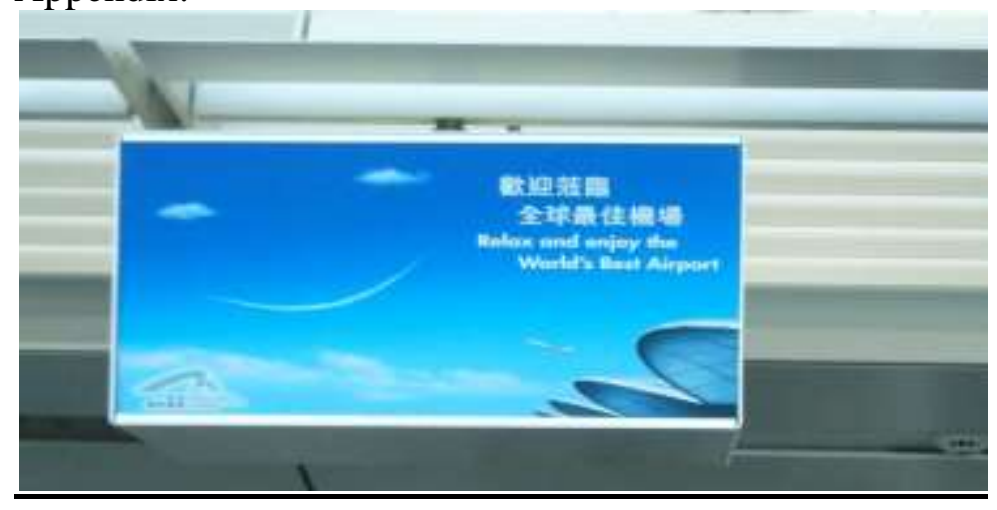

